\title{
GENETICS OF LEAD TOLERANCE IN FESTUCA OVINA
}

\author{
C. URQUHART * \\ Department of Botany, University of Birminghom
}

Received 6.ii.70

\section{Introduction}

Adaptation to concentrations of metals which are normally toxic has been described in all classes of plants from micro-organisms to vascular plants (e.g. see the reviews by Ashida, 1965, and Rune, 1953). Few experimental investigations, however, have been made into the genetics of such adaptation. McNeilly and Bradshaw (1968) tested populations of Agrostis tenuis Sibth. for copper tolerance using tillers and seed material from various mine tips and showed that copper tolerance had a high heritability, but the only previous measurements on progenies derived from parent plants of known metal tolerance are those of Wilkins (1960), who measured lead tolerance in Festuca ovina L., and Bröker (1963), who measured zinc tolerance in Silene inflata. All these authors concluded that metal tolerance was an inherited characteristic, but whereas Wilkins (1960) thought that lead tolerance was under the control of a small number of genes, or even a single major gene, the other authors favoured polygenic systems. One factor contributing to the uncertainty of the mode of inheritance is the lack of precision in the measurement of heavy metal tolerance. As a consequence it was not possible to be sure whether the variation found in the progenies was continuous or discontinuous. In an attempt to overcome this problem the present investigations set out to collect data which could be analysed by statistical methods.

A number of plant species are found growing on lead-mine tips in Great Britain, but one of the most widespread is Festuca ovina L. This is a tussockforming grass, which therefore does not spread rapidly, and consequently the risk of multiple sampling of the same genotype from any one site is reduced. It is also easily grown as clones in garden soil, and tillers can be readily separated off for experimental work. However, $F$. ovina occurs in various polyploid races as well as in the diploid form (Watson, 1958), and as most of the available diploid material came from the North Pennine district the results relate directly only to the populations in that area.

\section{MATERIAL AND METHODS}

All the Festuca ovina plants used in this investigation, except plant 262, had been collected from, or near, lead-spoil tips in the North Pennines (see table 1). Subsequently, the clones were grown in ordinary garden soil, many of them for up to 13 years, before being used in the experiments described below. Each plant was given a reference number on collection which was used for identification in the experimental work.

Crossing was carried out in a glasshouse using portions of diploid $(2 n=14)$ material which had been potted-up for the purpose. Bunches of inflorescences of the required parent plants were enclosed together in crossing

* Present address : Department of Biological Sciences, University of Aston in Birmingham. 
bags just as the flowers of each plant began anthesis. Any fully open flowers were removed before the bags were put on, and after flowering was completed the inflorescences of each genotype were separated into individual bags. The diploid race is virtually self-sterile, but as a few individuals had occasionally been found to be slightly self-fertile a check was made by bagging a number of inflorescences of each parent separately. The success of a cross was estimated from the number of seedlings obtained per inflorescence.

\section{TABLE 1}

Description and location of the sites from which the experimental plants were collected. Lead tolerance indices (T.I.) of the plants and their 95 per cent. confidence limits, calculated from $\mathrm{n}$ values, are given

\begin{tabular}{|c|c|c|c|c|c|c|c|}
\hline $\begin{array}{l}\text { Plant } \\
\text { No. }\end{array}$ & T.I. & $\begin{array}{c}95 \% \\
\text { C.I. }\end{array}$ & $n$ & Location & $\begin{array}{l}\text { Nat. } \\
\text { Grid. Ref. }\end{array}$ & Vegetation & $\begin{array}{l}\text { Soil Pb } \\
\text { (ppm) }\end{array}$ \\
\hline 262 & $2 \cdot 52$ & $0 \cdot 10$ & 10 & Sarrowcole & NS 880144 & Field below tip & - \\
\hline 680 & $2 \cdot 29$ & $0 \cdot 16$ & 15 & Newshiel & NY 723482 & Flat area before tip & 0 \\
\hline 685 & $2 \cdot 16$ & 0.09 & 9 & Newshiel & & & \\
\hline 690 & $1 \cdot 22$ & - & 3 & High Raise 1 & NY 765460 & $\begin{array}{l}\text { Small bare patch with } \\
F \text {. ovina and Minu- } \\
\text { artia verna }\end{array}$ & 30,400 \\
\hline 692 & $1 \cdot 31$ & $0 \cdot 26$ & 9 & High Raise 2 & NY 765460 & $\begin{array}{l}\text { Small tip, partly bare } \\
\text { with } F \text {. ovina and } M \text {. } \\
\text { verna }\end{array}$ & 35,300 \\
\hline 693 & $1 \cdot 47$ & 0.62 & 4 & High Raise 2 & & & \\
\hline 702 & $2 \cdot 11$ & $0 \cdot 19$ & 7 & High Raise 3 & NY 765460 & $\begin{array}{l}\text { Big tip with turf in- } \\
\text { cluding } F \text {. ovina, } F \text {. } \\
\text { rubra, Agrostis, Ceras- } \\
\text { tium }\end{array}$ & 0 \\
\hline 703 & $1 \cdot 64$ & 0.09 & 10 & High Raise 3 & & & \\
\hline 704 & $1 \cdot 85$ & $0 \cdot 13$ & 6 & High Raise 3 & & & \\
\hline 705 & $1 \cdot 85$ & $0 \cdot 12$ & 13 & High Raise 3 & & & \\
\hline 708 & $2 \cdot 27$ & $0 \cdot 22$ & 5 & High Raise 3 & & & \\
\hline 728 & $1 \cdot 51$ & $0 \cdot 13$ & 10 & Nunnery 4 & NY 770427 & Old grassy tip & 88 \\
\hline 742 & 1.83 & 0.07 & 10 & Nunnery 2 & NY 772430 & Old grassy tip & 2,000 \\
\hline 743 & $1 \cdot 45$ & 0.05 & 10 & Nunnery 2 & & & \\
\hline 747 & $1 \cdot 56$ & 0.06 & 10 & Nunnery 1 & NY 772430 & $\begin{array}{l}\text { Tip with } F \text {. ovina and } \\
F \text {. rubra }\end{array}$ & 2,850 \\
\hline 752 & 1.46 & $0 \cdot 10$ & 10 & Nunnery 1 & & & \\
\hline 772 & $1 \cdot 00$ & - & - & Dun Fell 2 & NY 720320 & $\begin{array}{l}\text { Flat area below tip. } \\
F \text {. ovina, Deschampsia } \\
\text { flexuosa, } M \text {. verna }\end{array}$ & 30,000 \\
\hline 916 & $1 \cdot 06$ & $0 \cdot 11$ & 10 & Silverband l & NY 705320 & $\begin{array}{l}\text { Long ridge at side of } \\
\text { big hush. Clumps of } \\
F \text {. ovina, a little } D \text {. } \\
\text { fexuosa }\end{array}$ & 520 \\
\hline
\end{tabular}

The plants were tested for lead tolerance by the method of Wilkins (1960), in which root elongation was measured before and after addition of lead to the test solution, incorporating the device to lift the tillers out of the solution for several minutes every hour. This procedure ensured aeration and mixing of the experimental solutions. Linear extension of roots produced from tillers of each genotype was measured at a constant temperature $\left(25^{\circ} \mathrm{C}\right.$. $)$ and with continuous light (300 ft-c). Either the longest root in each of five tubes or, in later testing, the three longest roots in each of two tubes were measured and the mean tolerance index (T.I.) determined for each plant. The plants most tolerant of lead had the lowest tolerance indices. 
Statistical analysis of two sets of diallel cross data were carried out by Dr B. Barnes using the methods devised by Jinks (1954), Hayman (1954) and Jones (1965).

The amount of lead in the soil samples was estimated by a polarographic method following extraction with $0 \cdot 5 \mathcal{N}$ acetic acid.

\section{Results}

\section{(a) Diallel crosses}

The first diallel cross was made between five medium tolerant plants (collection numbers 728, 742, 743, 747 and 752) which came from three adjacent tips on Nunnery Hill (see table 1), and the second cross used plants 916,703 and 262 which came from widely separated habitats and showed extreme differences in lead tolerance. In each case the plants were crossed

TABLE 2

Mean tolerance indices of reciprocal progenies derived from four crosses

\begin{tabular}{lcccc}
\multicolumn{1}{c}{ Cross } & $\begin{array}{c}\text { Progeny } \\
\text { mean }\end{array}$ & $\begin{array}{c}\text { Reciprocal } \\
\text { mean }\end{array}$ & Difference & Significance \\
$916 \times 703$ & 1.45 & 1.64 & $0 \cdot 19$ & $\mathrm{P}<0.05$ \\
$916 \times 772$ & 1.10 & 1.28 & $0 \cdot 19$ & $\mathrm{P}<0.01$ \\
$703 \times 7 / 3,2$ & 2.31 & 1.98 & 0.32 & $\mathrm{P}<0.01$ \\
$29 / 0,4 \times 262$ & 1.77 & 1.65 & 0.12 & N.S.
\end{tabular}

in all possible combinations, but only one of the reciprocal crosses was grown and tested on the assumption that there were no maternal effects. Ten progeny were tested from each cross, and information about the parents was obtained from an equivalent number of samples of cloned material for each plant.

The analysis makes the following assumptions:

(1) no genotype-environment interaction,

(2) diploid segregation,

(3) no maternal effects,

(4) homozygous parents,

(5) no non-allelic gene interactions,

(6) no multiple alleles,

(7) uncorrelated gene distribution in the parents.

Of these assumptions only number 6 is untestable. Because tolerance was maintained by the plants after several years in cultivation, and since tests carried out on a number of plants at various times of the year gave consistent results, it was considered that genotype-environment interaction could be ruled out for this character. The second assumption of diploid inheritance was valid as only diploid plants were used. There was some evidence in this material of significant maternal effects (table 2), however these effects were considered to be relatively trivial. The remaining assumptions $(4,5$ and 7) can be tested for the first half-diallel by means of the covariance-variance analysis of Jinks $(1954,1956)$ and Dickinson and Jinks (1956). If there is evidence of non-additive genetic variation from the analysis of variance, then the points of the $W r / V r$ graph (see fig. 2) are expected to lie on a straight line of unit slope when the parents are homo- 
zygous and have uncorrelated gene distributions, and where there is no nonallelic interaction. Failure of these assumptions causes a characteristic disturbance of this relationship.

The mean tolerance indices of the parents and progeny used in the halfdiallel cross involving the five North Pennine plants are given in table 3, and the corresponding analysis of variance in table 4. (The primary data have been plotted as histograms in fig. 1.) Additive genetic variation was shown by the significance of the $a$ mean square, and the significant $b$ items

TABLE 3

Mean tolerance indices for the first diallel cross (see text)

$\begin{array}{cccccc}\text { Plant No. } & 743 & 752 & 728 & 747 & 742 \\ 743 & \mathbf{1 . 4 4 5} & 1.299 & 1.340 & 1.369 & 1.380 \\ 752 & & \mathbf{1 . 4 5 6} & 1.490 & 1.457 & 1.377 \\ 728 & & & \mathbf{1 . 5 0 7} & 1.600 & 1.662 \\ 747 & & & & \mathbf{1 . 5 6 2} & 1.536 \\ 742 & & & & & \mathbf{1 . 8 3 0}\end{array}$

showed non-additive genetic variation. Since the regression of $\mathrm{Wr}$ on $\mathrm{Vr}$ (fig. 2) was a straight line of slope not significantly different from $1 \cdot 0$, this latter variation may be interpreted as dominance and not as non-allelic interaction. Directional dominance was indicated by the significance of the $b_{1}$ item and showed that the means of the crosses were, on average, signifcantly different from the means of the parents. Furthermore, the $b_{2}$ item indicated that there were differences in dominance between the parental lines. The level of dominance may be judged from the intersection of the

Table 4

Analysis of variance for the first diallel cross (see text)

$\begin{array}{crrr}\text { Item } & \text { d.f. } & \text { M.S. } & \mathbf{P} \\ a & 4 & 0 \cdot 03948 & <0 \cdot 1 \% \\ b_{1} & 1 & 0 \cdot 03960 & 1-0 \cdot 1 \% \\ b_{2} & 4 & 0 \cdot 01350 & 5-1 \% \\ b_{3} & 5 & 0 \cdot 00320 & \\ \text { Error } & 133 & 0.00466 & \end{array}$

regression line with the $W r$ axis of the graph. For this purpose the intersection of the regression line with the axes shown in pecked lines should be considered. These axes have been displaced by an amount proportional to the environmental component of variation, derived from the analysis of variance, appropriately calculated for $V r$ and $W r$. As the intercept of the $W r$ axis was positive but near the origin (fig. 1) this indicated that dominance was almost complete.

Further information on the type of dominance shown for lead tolerance may be obtained as follows. The positions of the points along the regression line give a measure of the relative number of dominant and recessive genes in the parental lines, and the parents with most dominant genes occur near the origin. These are seen to be the lead-tolerant plants, while the nontolerant plants, with recessive genes, take large values of both $W r$ and $V r$. The correlation between $(W r+V r)$ and the parental tolerance indices was 0.931 . Thus, dominance was directional and for lead tolerance. The actual number of genes determining lead tolerance could not be estimated from 
these data, but two or more genes must have been involved, since if only a single major gene had been concerned the points would have occurred as a cluster at each end of the regression line.

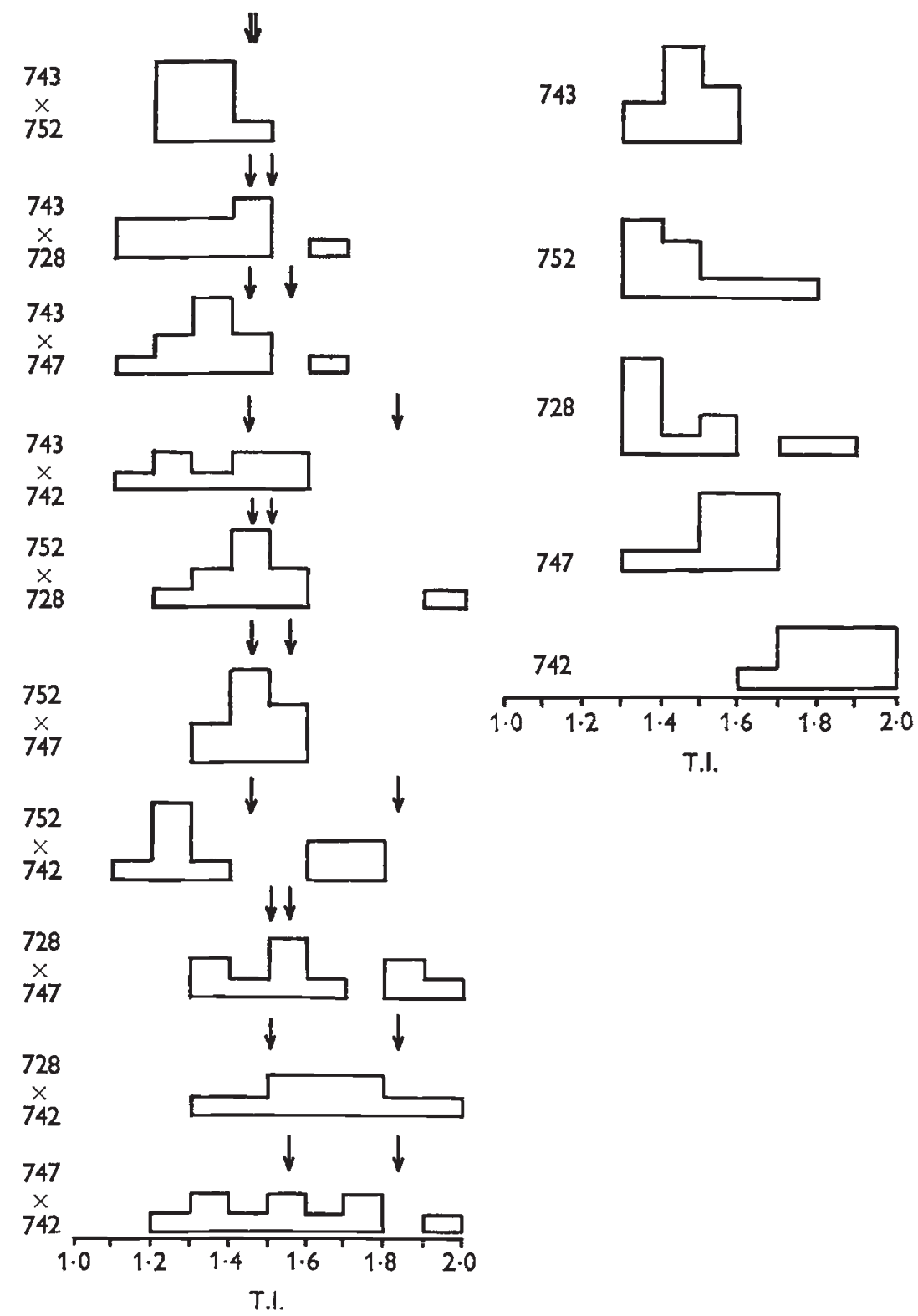

Fro. 1.-Graphical representation of the data from the first half diallel cross (see text).

The data from the second diallel cross support these findings in general (see tables 5 and 6), i.e. highly significant additive and non-additive variation. However, there were insufficient data for a variance/covariance analysis to be carried out. 


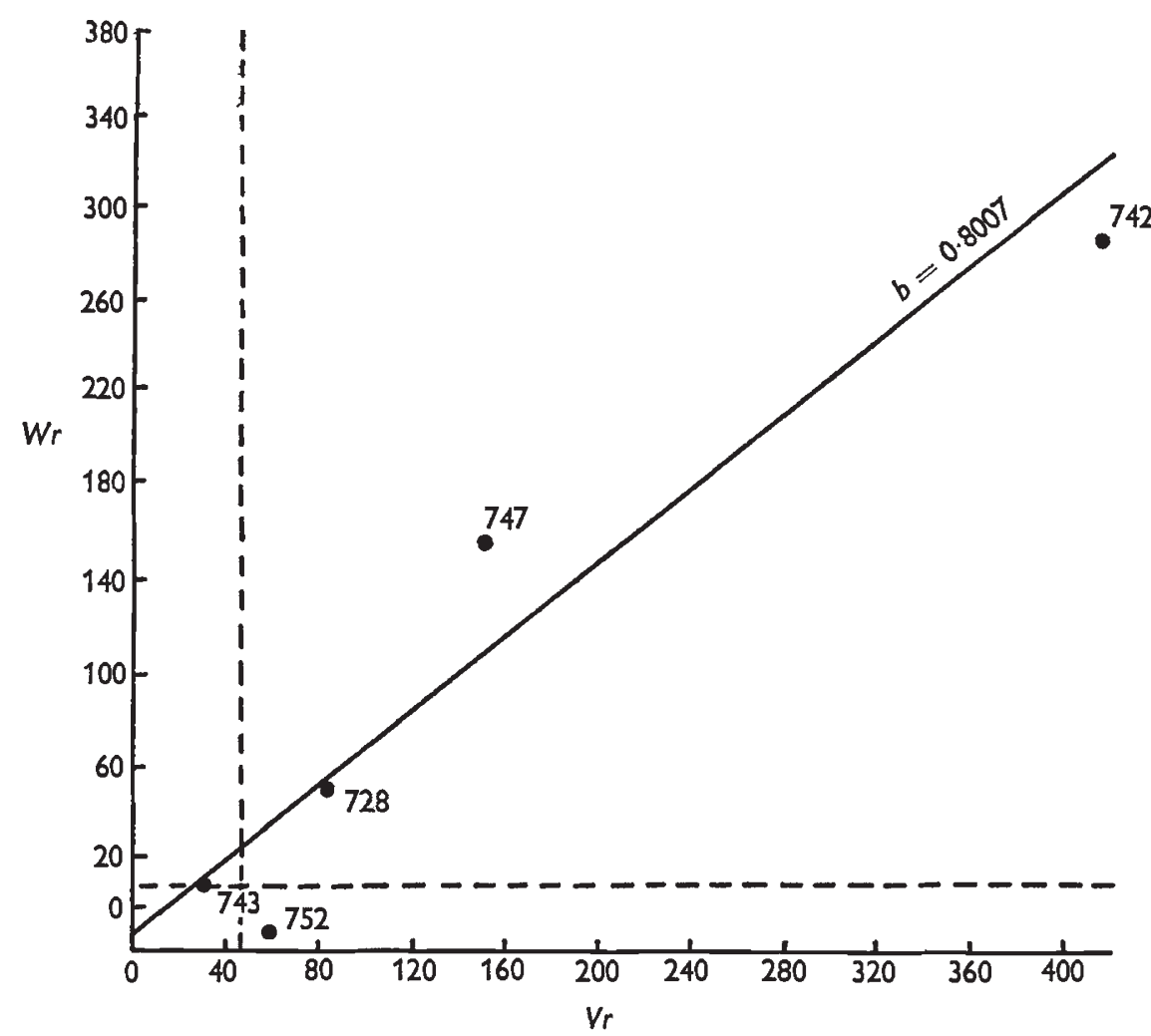

FIG. 2.-Covariance; variance graph for lead tolerance in the first half diallel cross (see text). The pecked axes indicate the correction to ordinate and abscissa due to the environmental component.

\section{TABLE 5}

Mean tolerance indices for the second diallel cross (see text)

$\begin{array}{cccc}\text { Plant No. } & 916 & 703 & 262 \\ 916 & \mathbf{1 . 0 6 0} & 1.469 & 1.567 \\ 703 & & \mathbf{1 . 6 4 1} & 1.892 \\ 262 & & & \mathbf{2 . 5 2 1}\end{array}$

Table 6

Analysis of variance of the second diallel cross (see text)

$\begin{array}{lrrc}\text { Item } & \text { d.f. } & \text { M.S. } & \text { P } \\ a & 2 & 5.6175 & <0.1 \% \\ b_{1} & 1 & 0.1441 & <0.1 \% \\ b_{2} & 2 & 0.2836 & <0.1 \% \\ \text { Error } & 54 & 0.0043 & \end{array}$

(b) Crosses between selected wild plants

The genetics of lead tolerance was further studied in a series of crosses between plants of known tolerance. Figures 3 and 4 show the results of crossing the non-tolerant plants 702 and 262 with non-tolerant, medium 
tolerant and tolerant plants. In both cases crossing with another nontolerant plant gave non-tolerant progenies with a small number of medium tolerant individuals; the spread increased when crossed with a medium tolerant plant (703); and with a tolerant plant (916) the progenies showed a
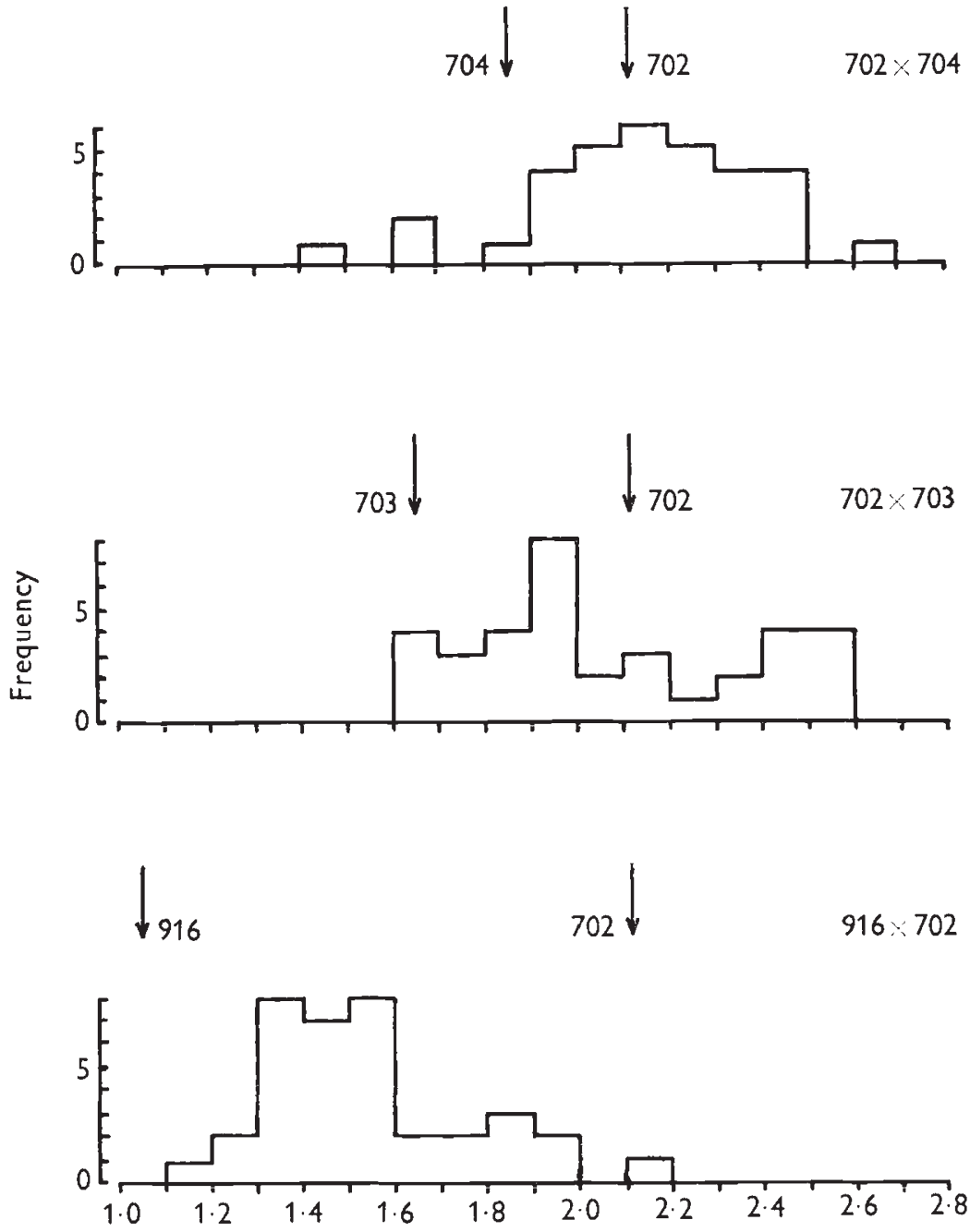

T.I.

FIG. 3.-Progenies derived from crossing the non-tolerant plant 702 with non-, medium and tolerant plants.

high degree of dominance for tolerance. The progenies from the crosses of the tolerant plants $772 \times 916$ and $692 \times 693$ were also highly tolerant (fig. 5). However, the dominant character of tolerance was not shown when plant 916 was crossed with the medium tolerant 703 (fig. 5). Similarly, when the tolerant plant 690 was crossed with the non-tolerants 708 and 702 (fig. 5) and in the backcross $29 / 0,4 \times 262$ (fig. 9) no dominant effects were apparent. Neither were any dominance effects apparent in crosses between non-tolerant 
plants, i.e. $702 \times 704$ (fig. 3), $708 \times 262$ (fig. 4), $704 \times 708,685 \times 680$ and the self progeny of plant 680 (fig. 6).
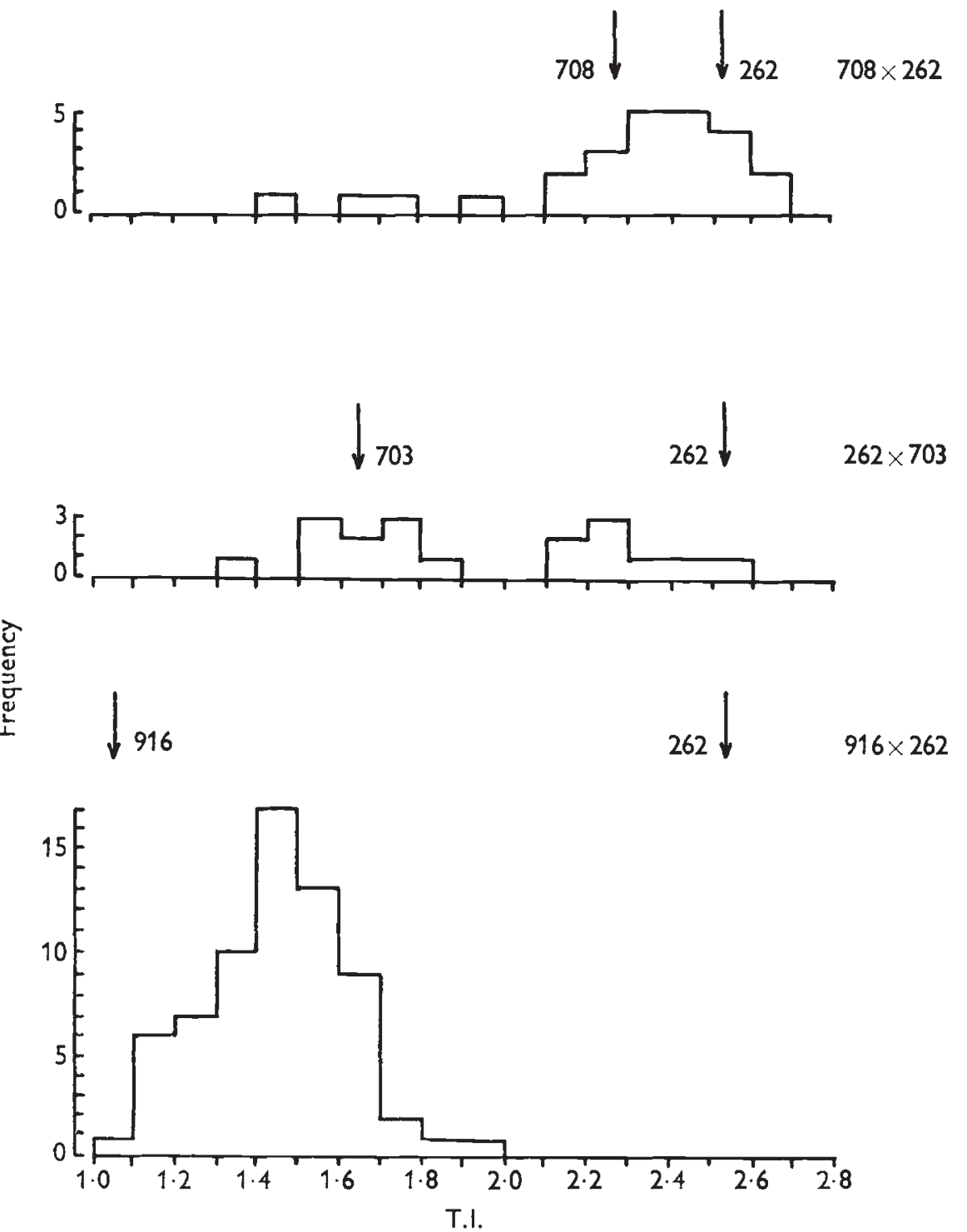

Frg. 4.-Progenies derived from crossing the non-tolerant plant 262 with non-, medium and tolerant plants.

No dominance for tolerance, but rather dominance towards non-tolerance, was indicated from the cross of the two medium tolerant plants 705 and 703 and from the self-fertilised progeny of plant 703 (see fig. 5). Some doubt existed about the cross $703 \times 705$, however, since the fertility was so low that the seedlings could have been produced as a result of self-fertilisation of 


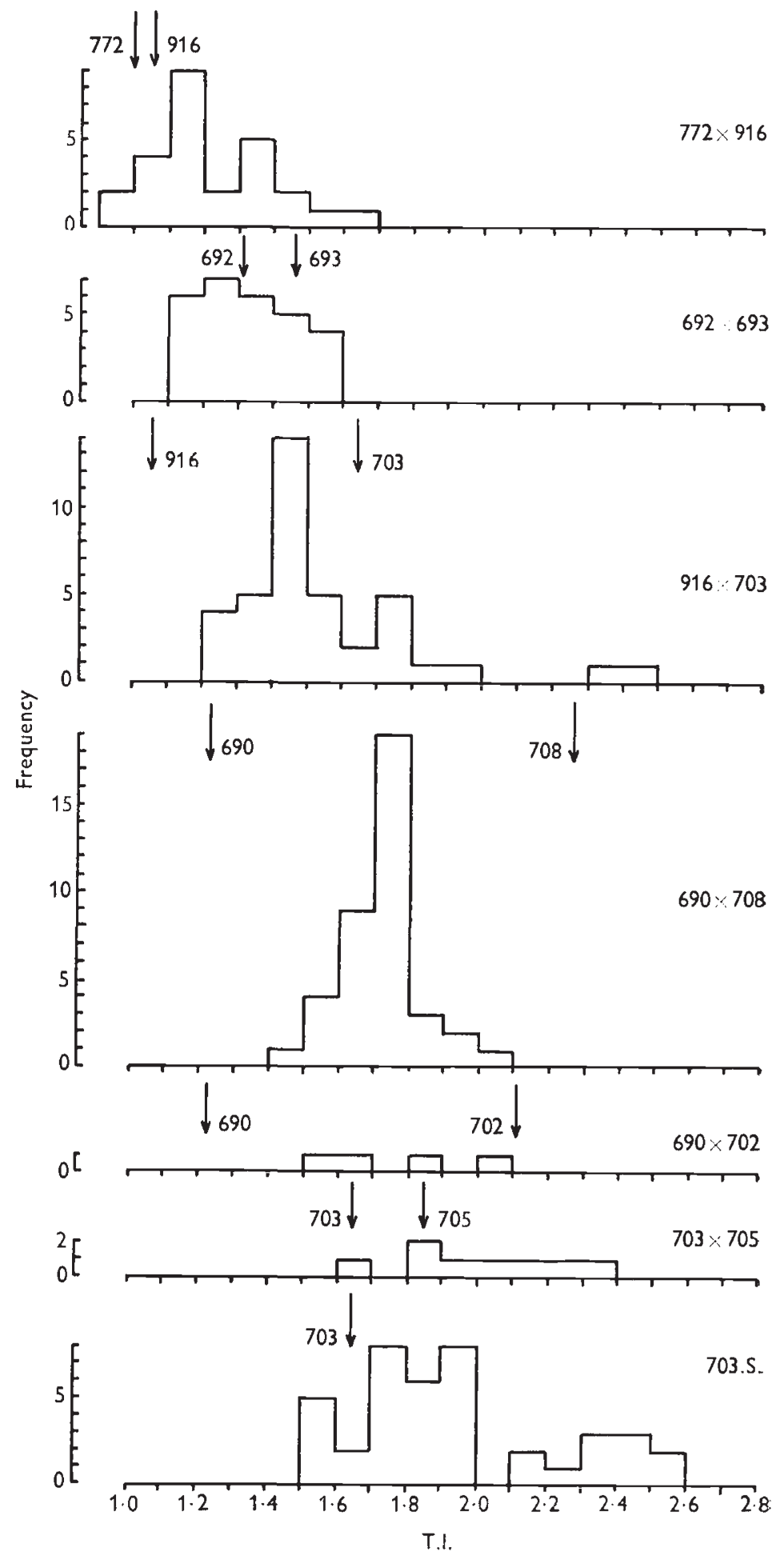

FrG. 5.-Examples of crosses not showing dominance for tolerance. 
plant 703, and would thus only be giving a second estimate of that progeny. More positive evidence for dominance of non-tolerance came from the second cross and backcross data presented in figs. 7 and 8 . This was most obvious in the backcrosses of plants $7 / 3,2$ and $9 / 2,4$ to plant 703 (figs. 7 and 8 respectively).
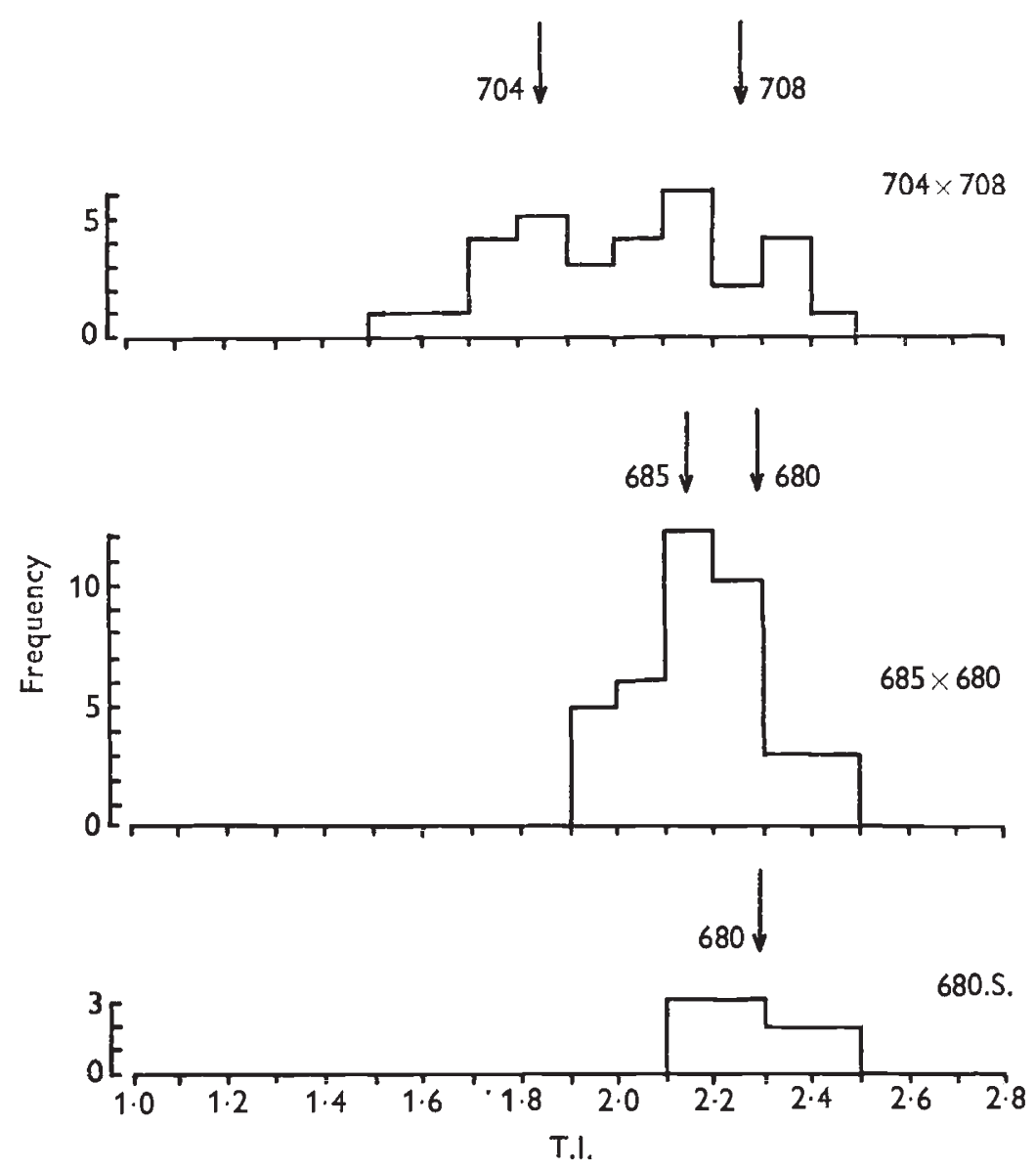

FIG. 6.-Progenies from non-tolerant parents.

Modification of dominance is seen in figs. 8 and 9. For instance, in fig. 8 , whereas no dominance was shown in the original cross $(702 \times 703)$ the second cross $(9 / 5 \times 9 / 4)$ gave a progeny in which tolerance was dominant. Backcrosses of plants $9 / 0,1$ and $9 / 2,4$ to the non-tolerant parent (702) produced progenies in which no dominance was shown, but as mentioned above, a backcross of $9 / 2,4$ to the medium tolerant parent (703) gave a progeny in which non-tolerance showed almost complete dominance. Similarly, in the first cross of plants 916 and 262 (fig. 9) dominance was shown to be almost complete for tolerance. However, this broke down and no dominance was shown in the second cross $(29 / 7,3 \times 29 / 1,0)$ or the backcross of the tolerant $29 / 0,4$ with the non-tolerant parent (262). 


\section{Discussion}

The results presented in this investigation show clearly that lead tolerance in Festuca ovina is an inherited characteristic. Furthermore, the variation seems to be continuous, as Bradshaw et al. (1965) concluded for copper tolerance in Agrostis tenuis. Consequently, the discontinuities which Wilkins (1960) looked for in Festuca ovina were not to be found and the character could not, therefore, be under the control of a single major gene.
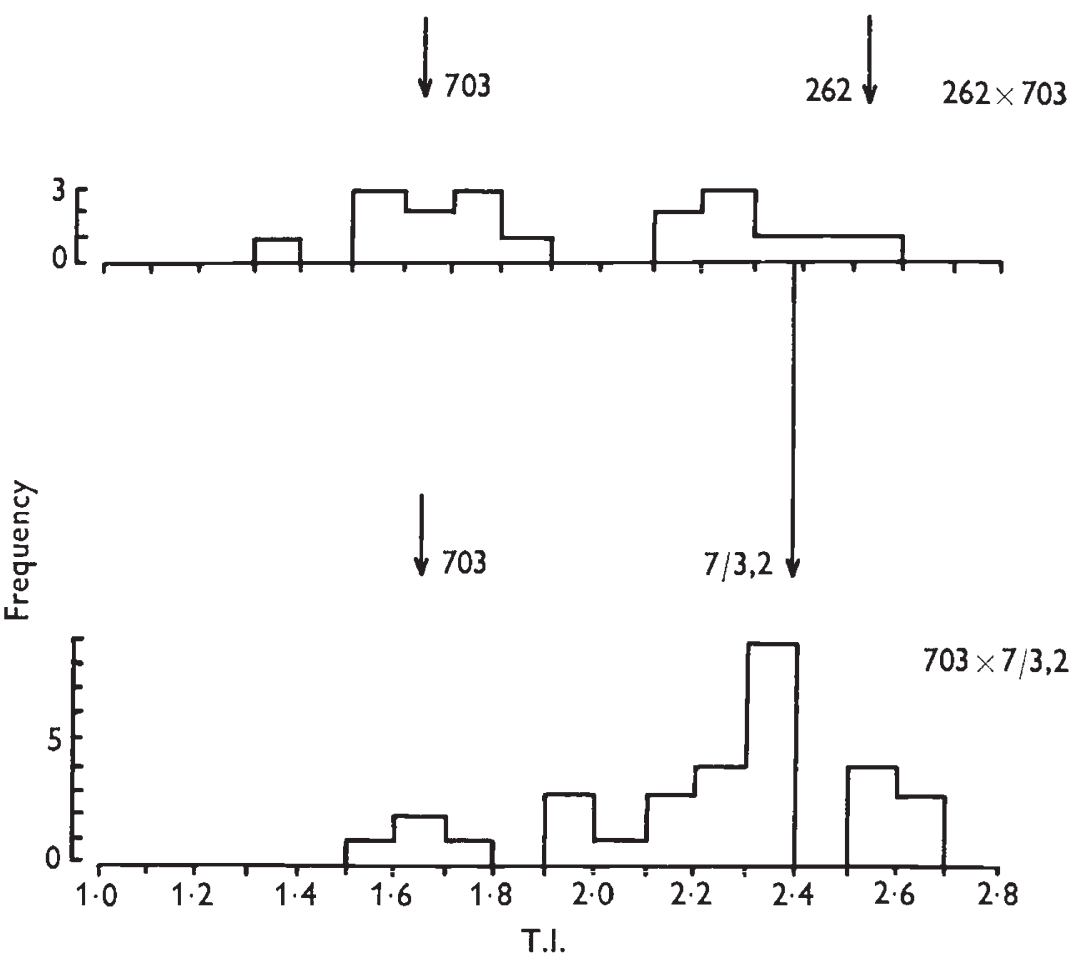

FIG. 7.-Backcross to plant 703 showing dominance for non-tolerance.

Bradshaw et al. (1965) concluded that tolerance of heavy metals was dominant in Agrostis tenuis, whereas McNeilly and Bradshaw (1968) found no obvious dominance for copper tolerance. Previously, Wilkins (1960) had concluded that lead tolerance in Festuca ovina tended to be dominant, although he also found instances in which this was not shown. Lead tolerance was found to be dominant in some of the crosses reported here (e.g. figs. 3 and 4) and both diallel analyses demonstrated strong directional dominance. However, it was also apparent that the degree of dominance could vary, and that in some instances it was absent (e.g. fig. 5) while in others non-tolerance exhibited dominance (figs. 7 and 8). This evidence confirmed the hypothesis made by Antonovics (1968) that effects of dominance could be ambidirectional but that the severe selection pressures on metal contaminated soil would, on the whole, select for dominance of tolerance. These results also indicated that dominance may still be evolving and that the modifiers controlling level and direction had not yet been fixed by selection. 
Dominance of characters in other organisms has also been shown by means of artificial crosses to be a variable and genetically controlled factor (e.g. Whitten (1968), see also for further refs.), and Sheppard and Ford (1966) stated that artificial selection experiments indicated the presence of modifiers controlling dominance. It is possible, therefore, that the expression of

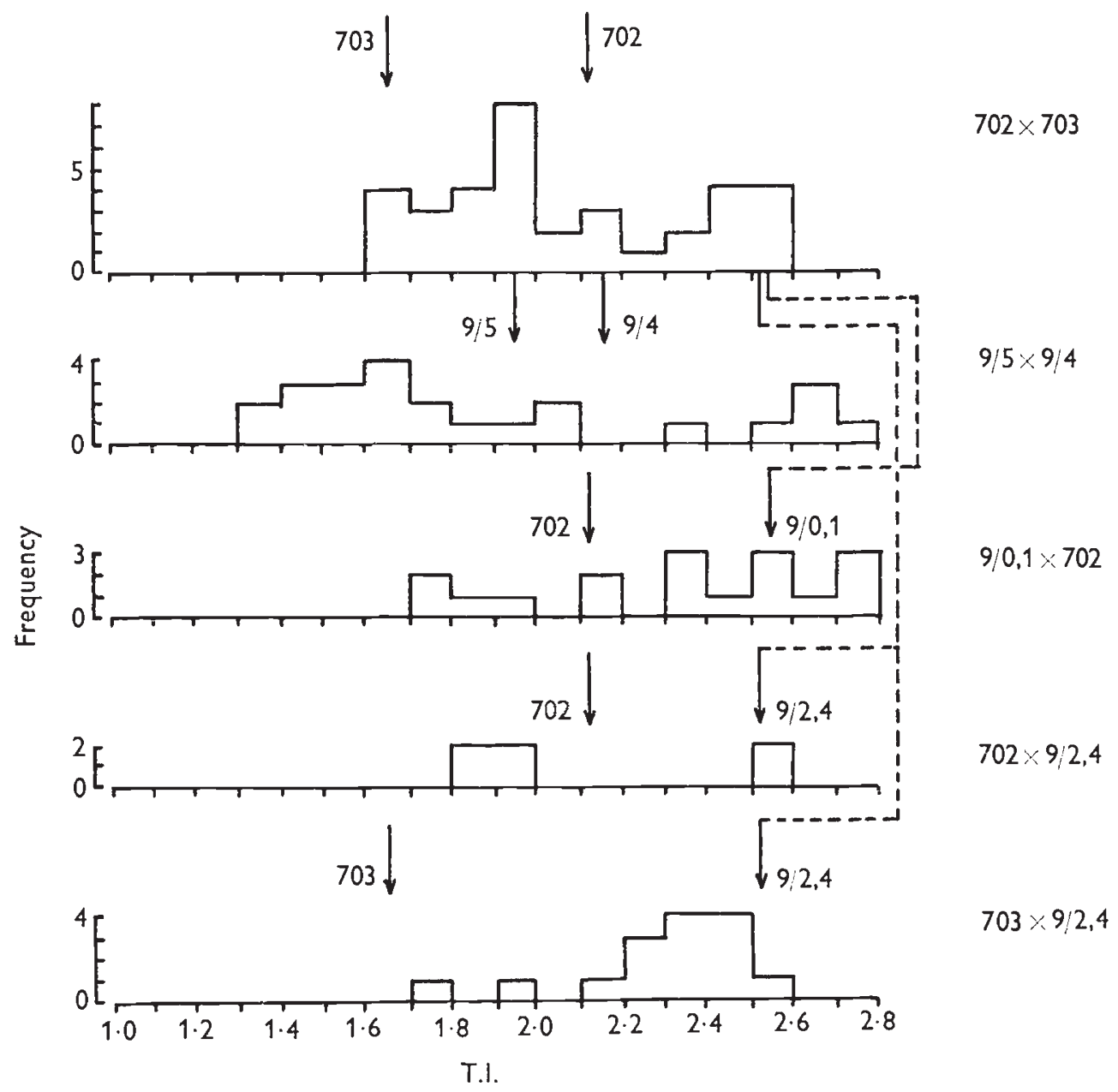

FIG. 8.-First, second and backcross generations derived from medium and non-tolerant parents.

dominance for lead tolerance in Festuca ovina is under the control of specific modifiers, which Antonovics' (1968) model predicts could spread rapidly through mine populations in the presence of gene flow from surrounding normal pasture populations. The model also showed that overdominance of the favoured gene could be produced. However, in this material there was no evidence for overdominance.

That populations could diverge without any isolation limiting gene flow between them had, for example, been found for Drosophila by Thoday and Boam (1959), and predicted from mathematical models by Clarke (1966) 
and Jain and Bradshaw (1966). Continuous variation in the expression of lead tolerance could probably, therefore, be accounted for on the basis of major control by a small number of genes the dominance of which is con-

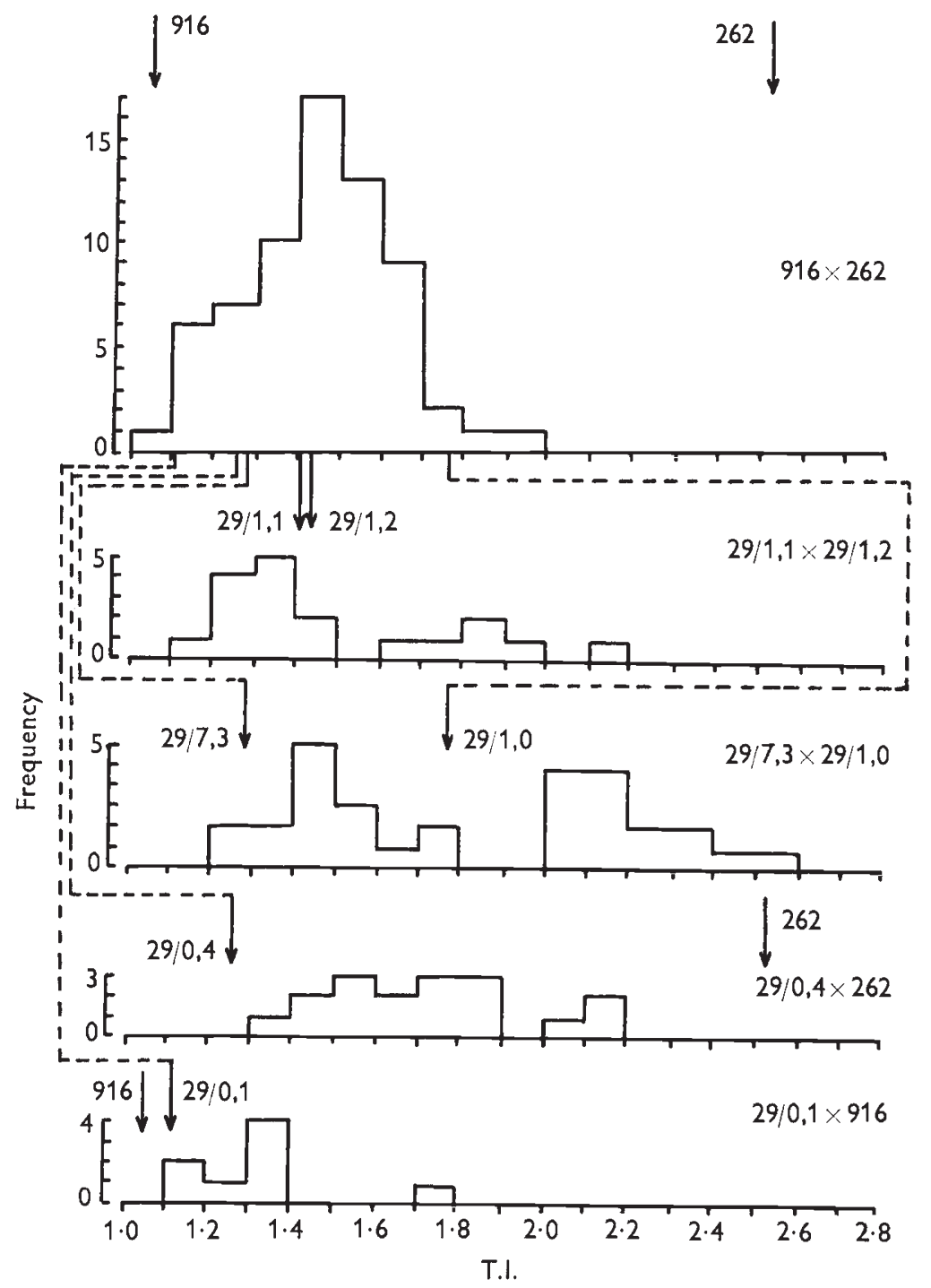

Fig. 9. - First, second and backcross generations derived from the tolerant and non-tolerant parents 916 and 262.

trolled by modifiers, and the overall expression of which is affected to a small degree by maternal effects (see table 2).

It is implicit from the discussion by Bradshaw et al. (1965), concerning the evolution and place of origin of heavy metal tolerance, that they consider tolerance to have evolved by the prdouction of compounds within the plants specifically for protection against the toxic effects of heavy metals. Certainly 
the mechanisms appear to be specific in that tolerance of one metal does not impart tolerance of another (Gregory and Bradshaw, 1965), but a mechanism such as that described by Ashida (1965) seems a much simpler explanation. He suggested that adaptation to metal toxicants might be adventitious by the intensification of some normal physiological activity, and individuals possessing this heightened activity would be selected. A tolerance mechanism of this sort could be selected from any population of the species and would obviate discussions as to the place of origin and spread of tolerant plants. The progenies produced from crosses between two tolerant parents (fig. 5) or two extremely non-tolerant plants (fig. 6), for example, show that although variation of tolerance is continuous there are limits, and that the extreme, wild parent types approach these limits. Hence, no new or mutant type of plant need be produced.

It is generally assumed that the toxic metal will be chelated within the plant and selectivity of the metal tolerated would therefore arise from the specificity of the chelating compound produced. Where a plant was tolerant of more than one metal, an equivalent number of tolerance mechanisms would have been selected for. However, not all plants have the ability to develop races tolerant of contaminated soil, as is evidenced by the sharp reduction in species numbers when passing from uncontaminated on to contaminated soil (Rune, 1953). Consequently, one must assume that only those species which possess sufficient flexibility in the control of the necessary metabolic processes can invade contaminated areas. On the other hand, it is obvious from the list of species possessing tolerance (Rune, 1953) that this ability is not restricted to any particular class of plants.

\section{Summary}

1. The genetical basis of lead tolerance within the species Festuca ovina has been investigated by means of the analyses of half diallel crosses, and by a series of crosses between selected parents of known tolerance.

2. Analysis of the diallel cross data showed additive genetic variation and directional dominance for lead tolerance. There was no evidence of non-allelic interaction.

3. Examination of the selected crosses showed that the degree of dominance, and even the direction of dominance varied.

4. There were indications of small maternal effects.

5. It was concluded that more than one, but probably a small number of genes, were producing the major effects, and that modifiers for dominance were present. These latter were probably affected, in turn, by the genome as a whole.

6. The data were discussed in relation to theories of the evolution of heavy metal tolerance on mine tips.

Acknowledgments. - I would like to thank Dr D. A. Wilkins for the use of his plant collection and soil analysis data, and Dr B. Barnes of the Department of Genetics for analysis of the diallel cross data. I am also grateful to them for valuable discussion and criticism of the manuscript. The work was financed by a Science Research Council grant.

\section{REFERENCES}

ANTonovics, J. 1968. Evolution in closely adjacent plant populations. VI. Manifold effects of gene flow. Heredity, 23, 507-524. 
AShIDA, J. 1965. Adaptation of fungi to metal toxicants. A. Rev. Phytopath., 3, 153-174. BRADSHAW, A. D., MGNEILLY, T. S., AND GREGORY, R. P. G. 1965. Industrialisation, evolution and the development of heavy metal tolerance in plants. Ecology and the Industrial Society, 5th Brit. Ecol. Soc. Symp., pp. 327-343. Blackwell, Oxford.

BRÖKER, w. 1963. Genetisch-Physiologische Untersuchungen uber die Zinkvertraeglichkeit von Silene inflata, Sm. Flora, Jena, 153, 122-156.

GLARKE, в. 1966. The evolution of morph-ratio clines. Am. Nat., 100, 389-402.

DiGkinson, A. G., AND JiNks, J. L. 1956. A generalised analysis of diallel crosses. Genetics, 41, 65-78.

GREGORY, R. P. G., AND BRADSHAW, A. D. 1965. Heavy metal tolerance in populations of Agrostis temuis Sibth. and other grasses. New Phytol., 64, 131-143.

HAYMAN, B. I. 1954. The analysis of variance of diallel tables. Biometrics, 10, 235-244.

JAIN, s. K., AND BRADSHAW, A. D. 1966. Evolutionary divergence among adjacent plant populations. I. The evidence and its theoretical analysis. Heredity, 21, 407-441.

JINKs, J. L. 1954. The analysis of continuous variation in diallel cross of Nicotiana rustica varieties. Genetics, 39, 767-788.

JiNks, J. L. 1956. The $\mathbf{F}_{2}$ and backcross generations from a set of diallel crosses. Heredity, 10, $1-30$.

JONES, R. M. 1965. Analysis of variance of the half diallel table. Heredity, 20, 117-121.

MCNEILLY, T., AND BRADSHAW, A. D. 1968. Evolutionary processes in populations of copper tolerant Agrostis tenuis Sibth. Evolution, 22, 108-118.

RUNE, O. 1953. Plant life on serpentine and related rocks in the north of Sweden. Acta phytogeogr. suec., 31, 1-139.

SHEPPARD, P. M., AND FORD, E. B. 1966. Natural selection and the evolution of dominance. Heredity, 21, 139-147.

THODAY, J. м., AND BOAM, т. в. 1959. Effects of disruptive selection. II. Polymorphism and divergence without isolation. Heredity, 13, 205-218.

Watson, P. J. 1958. The distribution in Britain of diploid and tetraploid races within the Festuca ovina group. New Phytol., 57, 11-18.

WHITTEN, M. J. 1968. Genetical control of penetrance and evolution of dominance in Drosophila. Heredity, 23, 263-278.

wILkINs, D. A. 1960. The measurement and genetical analysis of lead tolerance in Festuca ovina. Rep. Scott. Pl. Breeding Stn, pp. 85-98. 